\title{
METODOLOGIA PARA RECONHECIMENTO DE TRÊS SOLOS POR SENSORES: LABORATORIAL E ORBITAL ${ }^{(1)}$
}

\author{
J . A. M. DEMATTÊ (2), A. M. A. TOLEDO(3) \& M. S. SIMÕES ${ }^{(4)}$
}

\begin{abstract}
RESUMO
0 presente trabalho teve como objetivo estabelecer um método para a utilização de dados espectrais, obtidos em laboratório e imagens do Landsat 5, no reconhecimento e discriminação de três classes de solos do estado de São Paulo. Foram coletadas amostras de solo e obtidos os dados de reflectância por espectrorradiômetro em laboratório como padrão de um Latossolo Vermelho distroférrico (LVdf), um Argissolo Vermelho-Amarelo (PVA) e Neossolo Quartzarênico (RQ). Foram extraídos dados de reflectância das imagens, com os quais se efetuou a classificação digital pelo classificador Spectral Angular Mapper. As curvas espectrais obtidas por espectrorradiômetro em laboratório mostraram três padrões distintos de comportamento espectral, baseados nas diferenças da forma das curvas, feições de absorção dos minerais do solo e na intensidade de reflectância. O LVdf apresentou menor albedo em virtude da textura argilosa e maiores teores de $\mathrm{Fe}$, ao contrário dos solos mais arenosos PVA e RQ. As bandas de absorção características da caulinta $(2.200 \mathrm{~nm}), \mathrm{OH}^{-}$e água (1.400 e $1.900 \mathrm{~nm}$ ) ocorreram em todos os solos. Solos arenosos, como o RQ, apresentaram uma curva espectral com tendência positiva. A linha do solo mostrou distinção espectral, tanto com dados or bitais como terrestres, indicando que cada solo tem uma tendência individual. Os padrões espectrais obtidos em laboratório foram importantes para a eficiência do método na detecção dos mesmos nas imagens de satélite. Os solos avaliados podem ser discriminados e reconhecidos pela interpretação quantitativa em imagens. $\mathbf{O}$ método mostrouse eficiente como auxílio no mapeamento de solos no nível semidetalhado de alta intensidade.
\end{abstract}

Termos de I ndexação: classificação de solos, sensoriamento remoto, classificação digital, imagem de satélite, mapeamento, radiometria.

(1) Recebido para publicação em setembro de 2003 e aprovado em agosto de 2004.

(2) Professor do Departamento de Solos e Nutrição de Plantas, Escola Superior de Agricultura "Luiz de Queiroz" - ESALQ/USP. Av. Pádua Dias 11, CEP 13418-900 Piracicaba (SP). E-mail: jamdemat@carpa.ciagri.usp.br

(3) Doutorando do Centro de Energia Nuclear na Agricultura - CENA. Piracicaba (SP).

(4) Pesquisador da Coopersucar. Piracicaba (SP). 


\title{
SUMMARY: METHODOLOGY FOR THE RECOGNITION OF THREE SOILS BY USING LABORATORY AND ORBITAL SENSORS
}

\begin{abstract}
The objective of this research was to determine a methodol ogy for the use of spectral data obtained in the laboratory and from orbital images for the recognition and discrimination of thre soil classes in theState of São Paulo, Brazil. Reflectancedata were obtai ned by a spectroradiometer/ by Landsat 5 images in thelaboratory as standards from soil samples of Oxisol, Ultisol, and Entisol profiles. Orbital data wereconverted to reflectance and classified by the Spectral Angle Mapper. The spectral curves obtained by a spectroradiometer in thelaboratory showed threedifferent patterns, based on thedifferences in the shape of the curves, soil mineral absorption features, and the reflectance intensity. TheOxisol presented smaller reflectance due to the clayey texture and greater iron content, in relation to the sandier Ultisols and Psament. The characteristic absorption bands of kaolinite $(2,200 \mathrm{~nm}), \mathrm{OH}^{-}$, and water $(1,400$ and $1,900 \mathrm{~nm})$ occurred in all soils. Sandy soils such as thePsament presented a spectral curvewith positivetendency. Thesoils were discrimi nated by thei mages (bands 5 and 7), being theterrestrial sensor data an important support in this evaluation. The soil line showed spectral distinction for both orbital and terrestrial data, indicating an individual tendency for each soil. The spectral standards obtained in the laboratory were important for the efficiency of the methodology to identify thesamein thesatel liteimages. The methodol ogy was efficient to detect areas with exposed soil in the image. The methodol ogy showed that the soil classes used in this work can be recognized and discriminated by orbital data. The obtained results of the digital classification indicated that this technique can be used to support soil survey at a semidetailed level of high intensity.
\end{abstract}

Index terms: soil classification, remote sensing, digital classification, satel liteimages, soil survey, spectroradiometry.

\section{NTRODUÇÃO}

A pressão sobre a necessidade de maior produção dealimentos em virtude do aumento populacional tem causado sérios danos ao ambienteem geral e, em particular, aos solos. Tal efeito é resultante da intensa e desorganizada urbanização, industrial ização, desflorestamento e falta de planejamento do uso da terra. Portanto, existe uma necessidade urgentena sistematização do mapeamento e monitoramento das terras, como base para uma produção agrícola sustentável, preservando o ambiente.

O inventário sobre os solos pode ser realizado pel os métodos convencionais de levantamentos de sol os, estabelecidos por Brasil (1960). Por outrolado, o sol o também pode ser avaliado por métodos como os iniciados por Westin \& Frazee (1976) e Venkataratnam (1980). Geralmente, os métodos convencionais são trabal hosos, caros e demorados, quando comparados com as técnicas de mapeamento por sensoriamento remoto.

Da mesma forma que o mapeamento de solos evoluiu no Brasil (E mbrapa, 1999) e nos EUA (Soil Taxonomy, 1998), as técnicas auxiliares também evoluíram. Neste aspecto e dentre estas técnicas, o Sensoriamento Remoto (SR) vem-se destacando como uma importante ferramenta que pode auxiliar nos levantamentos de solos (Ben-Dor, 2002).

As aplicações de SR em pedol ogia começaram nos anos 30s com a utilização de fotografias aéreas como mapas-base. Nos anos 60s, um novo impulso ocorreu com o desenvolvimento de novas técnicas cartográficas aplicadas à pedologia, permitindo o estudo do padrão fisiográfico dos sol os. Atualmente, são avaliadas imagens de satélite, com sucesso em diversas áreas, como em levantamentos geológicos (Vincent, 1999), noinventário elevantamento do uso da terra, visandoà discriminação eao monitoramento de culturas (Zermiani et al., 1999).

Outra técnica que vem sendo avaliada é a radiometria em laboratório. Neste caso, Cipra et al . (1980) compararam medi das deespectrorradiômetros em laboratório com dados digitais do Landsat 1 e observaram que os valores foram altamente correl acionados para todos os comprimentos deonda. Harrison \& J ohnson (1982) concluíram que o uso de mapas espectrais orbitais melhoram a acurácia e a qualidade dos mapas de sol os.

Nos últimos trinta anos, a espectrorradiometria tem sido muito utilizada em estudos de solos (Stoner \& Baumgardner, 1981), haja vista ser considerada uma excelente base de apoio para o entendimento de dados orbitais, conforme destaca Huete (1996). Em relação aos solos tropicais, verifica-se a necessidade de maior aprofundamento no conhecimento espectral, como demonstram trabalhos realizados por Formaggio (1983), Epiphanio et al. (1992), Madeira Netto (1996) e Formaggio et al. (1996) e principal mente em relação aos dados orbitais. A mai or parte dos trabalhos de radiometria, tanto no nível terrestre como orbital, 
apresenta-se como material básico na caracterização dos solos, havendo necessidade de desenvolvimento de métodos que, efetivamente, sejam aplicados no levantamento de solos, conforme os realizados por Shiva Prasad et al. (1990) e Saha et al . (1990).

O fato de novos e modernos sensores estarem sendo constantemente atualizados e desenvol vidos justifica a importância dos trabal hos na área deSR, conforme destacado por Ben-Dor (2002). A disponibilidade de novos sensores orbitais com melhores resoluções, espectral eespacial, possibilitam o desenvol vimento e aperfeiçoamento de aplicações em estudos de solos. Dentre as novas técnicas, destaca-se o conceito de linha do solo (LS), que apresenta uma relação linear entre a reflectância do sol o exposto na faixa do vermel ho e a reflectância no infra-vermelho próximo. O conceito de linha do solo baseia-se no fato de que a reflectância de solos expostos determina uma curva linear para estes dois comprimentos de onda (Baret et al., 1993).

Utilizando este conceito, é possível determinar áreas que apresentam maior probabilidade de ter solo exposto, o que permite a inferência das propriedades espectrais de solo a partir de imagens orbitais. No entanto, uma das dificul dades no estudo de solo em nível orbital éidentificar locais cujo val or espectral seja principalmente de solo. Na região de Piracicaba (SP), onde a topografia do terreno dificulta a colheita mecanizada, observam-se extensas áreas com solo exposto resultante da queima e corte anual da cana-de-açúcar. Por essa razão, encontra-se aí uma excelente oportunidade dedesenvol ver pesquisa nessa região sucroal cooleira no sentido de esclarecer dúvidas quanto ao comportamento de dados espectrais obtidos pelo sensor no satélite e em laboratório, procurando elucidar as vantagens e desvantagens desses sistemas e el aborar métodos para o uso de ambos no mapeamento de solos.

Diante do exposto, o presente estudo teve como objetivos: (a) caracterizar três sol os do estado de São Paulo pela reflectância espectral no nível terrestre (espectrorradiômetro em laboratório, na faixa de 400 a $2.500 \mathrm{~nm}$ ), eorbital (Landsat 5 TM); (b) determinar um método que identifique os solos na imagem orbital, e (c) avaliar a aplicação das imagens or bitais como ferramenta auxiliar no levantamento de solos.

\section{MATERIAL E MÉTODOS}

O trabalho foi desenvolvido em áreas próximas aos municípios de Piracicaba eSão Pedro, estado de São Paulo, estando compreendidas na quadrícula de Piracicaba, mapa pedológico semidetalhado do Instituto Agronômico de Campinas (IAC), escala base 1:50.000 e de publicação 1:100.000 (Oliveira \& Prado, 1989). O clima regional, segundo o sistema Köeppen, é do tipo Cwa, ou seja, mesotérmico de inverno seco, em que a temperatura média do mês mais frio é inferior a $18{ }^{\circ} \mathrm{C}$ e, no mês mais quente, ultrapassa $22^{\circ} \mathrm{C}$. O índice pluviométrico deste tipo climático varia de 1.100 a $1.700 \mathrm{~mm}$ ea temperatura no mês mais quente oscila entre 22 e $24^{\circ} \mathrm{C}$.

Foram escol hidas três áreas com ocorrência dos sol os: Latossolo Vermelho distroférrico, Argissolo Vermelho-AmareloTb distrófico abrupto e Neossolo Quartzarênico distrófico. Os perfis foram descritos de acor do com Lemos \& Santos (1996). Como esses solos são constantemente comparados com a classificação anterior (Camargo et al., 1987), a classificação utilizada nas discussões é a seguinte: LR, Latossolo Roxo distrófico A moderado textura muito argilosa ou argilosa (Latossolo Vermel ho distroférrico), local izado entre $22^{\circ} 35^{\prime} 00^{\prime \prime}$ e $22^{\circ} 43^{\prime}$ $00^{\prime \prime S}$ e $47^{\circ} 30^{\prime} 00^{\prime \prime}$ e $47^{\circ} 35^{\prime} 00^{\prime \prime} \mathrm{W}$, desenvol vido de rochas da formação Serra Geral, constituída por basalto, arenito inter-trap e diabásio; PV, grupamento indiscriminado de Podzól icos Vermel hoAmarel os Tb abruptos A moderado textura arenosa/ argilosa ou média/argilosa (Argissolo VermelhoAmarel oTb distrófico abrupto), local izado entre $22^{\circ}$ $52^{\prime} 00^{\prime \prime}$ e $23^{\circ} 00^{\prime} 00^{\prime \prime S ~ S ~} 47$ ० $32^{\prime} 00^{\prime \prime}$ e $47^{\circ} 30^{\prime} 00^{\prime \prime}$ W, relacionados com o Grupo Tubarão, constituída por arenitos, siltitos, varvitos, tilitos, conglomerados e fósseis e RQ, Areia Quartzosa álica profunda e pouco profunda A moderado (Neossolo Quartzarênico distrófico), localizado entre $22^{\circ} 42^{\prime} 00^{\prime \prime}$ e $22^{\circ} 46^{\prime} 00^{\prime \prime} \mathrm{s}$ e $47^{\circ} 53^{\prime} 00^{\prime \prime}$ e $47^{\circ} 58^{\prime} 00$ " W, relacionada com a formação Botucatu-Pirambóia, constituída por arenitos, siltitos, fol hel hos e fósseis.

Foram coletadas amostras decinco perfis desolos, na profundidade de $0-20 \mathrm{~cm}$. Nas análises químicas dos solos, foram determinados: $\mathrm{pH}\left(\mathrm{CaCl}_{2}\right)$, maté ria orgânica, $\mathrm{P}, \mathrm{K}, \mathrm{Mg}^{2+}, \mathrm{Ca}^{2+}, \mathrm{Al}^{3+} \mathrm{eH}+\mathrm{Al}$ (Raij et al., 1987). Na análise granulométrica, foram determinados areia grossa e areia fina, silte e argila. A sílica, a alumina e o Fe total foram determinados pelo ataque sulfúrico (Camargo et al., 1986).

Para caracterizar os solos, também foram efetuadas análises mineralógi cas da fração argila de acordo comJ ackson (1969). A seguir, procedeu-se à separação granulométrica da fração areia (peneiração úmida), frações: siltee argila (decantação). Amostras da fração argila foram saturadas com $\mathrm{K}^{+} \mathrm{e} \mathrm{Mg}^{2+}$, posteriormente, transferidas para lâmina de vidro (esfregaço) e irradiadas por raios-X. As amostras de argila foram irradiadas num intervalo de 3 a 32 graus. Foram obtidos difratogramas das amostras saturadas com $\mathrm{K}+\mathrm{a} 25,350$ e $550^{\circ} \mathrm{C}$ e as saturadas com $\mathrm{Mg}^{2+}$ e glicoladas.

O trabalho apresenta quatro fases: (a) fase de obtenção de curvas espectrais sob condições de laboratório: refere-se à avaliação de dados espectrais de sol os localizados em três áreas distintas (áreasbase) próximas ao município de Piracicaba (SP). Essa éa fase de conhecimento das curvas espectrais, 
usando-se sensor em laboratório; (b) fase de calibração dos dados orbitais: nessas mesmas áreas, também são coletados dados de reflectância de imagens de satélite e comparados com os padrões terrestres, salvo as diferenças inerentes a cada equipamento; (c) fase de aplicação: outras três áreas (áreas-teste), onde ocorrem os mesmos solos (e outros) próximos ao município de São Pedro foram sel ecionadas. O software ENVI (versão 3.3) foi municiado de informações espectrais provenientes das imagens das áreas-base e realizou-se uma classificação supervisionada na área-teste, e (d) fase de verificação: os dados foram verificados de duas formas: pela sobreposição do mapa de solos preexistente (Quadrícula) e verificação no campo com o Sistema de Posicionamento Global (GPS).

Utilizou-se, em laboratório, o sensor IRIS, I nfra Red Intelligent Spectroradiometer, com resolução espectral de $2 \mathrm{~nm}$ entre 400 e 1.000 e de $4 \mathrm{~nm}$ entre 1.000 e $2.500 \mathrm{~nm}$. O sensor foi colocado a $27 \mathrm{~cm}$ de altura sobre as amostras de solo (secas a $45^{\circ} \mathrm{C}$ por
$24 \mathrm{~h})$, acondicionadas em uma placa de petri com diâmetro de $9 \mathrm{~cm}$, formando uma camada com espessura de $1,5 \mathrm{~cm}$. A fonte de iluminação, uma lâmpada halógena de $650 \mathrm{~W}$, com feixenão colimado para o plano visado, foi posicionada a $61 \mathrm{~cm}$ do recipiente amostral, com um ângulo zenital de $15^{\circ}$. Foi utilizada, como padrão de referência, uma placa branca, cali ibrada pela Labsphere (1996), cujos dados foram, posteriormente, corrigidos para $100 \%$. A energia que alimenta a lâmpada foi controlada por uma fonte de potência, evitando-se variações na corrente elétrica. A razão entre o fluxo radiante espectral refletido pela superfície de uma amostra de sol o e o fluxo radiante espectral refletido por um padrão de referência, iluminados e visados sob as mesmas condições geométricas, gera o "fator de reflectância bidirecional espectral". Foram feitas três leituras por amostra, sendo utilizada a média para a avaliação. A partir do fator de reflectância bidirecional dos solos, obtiveram-se as curvas dos sol os sob condições de laboratório (Figura 1).

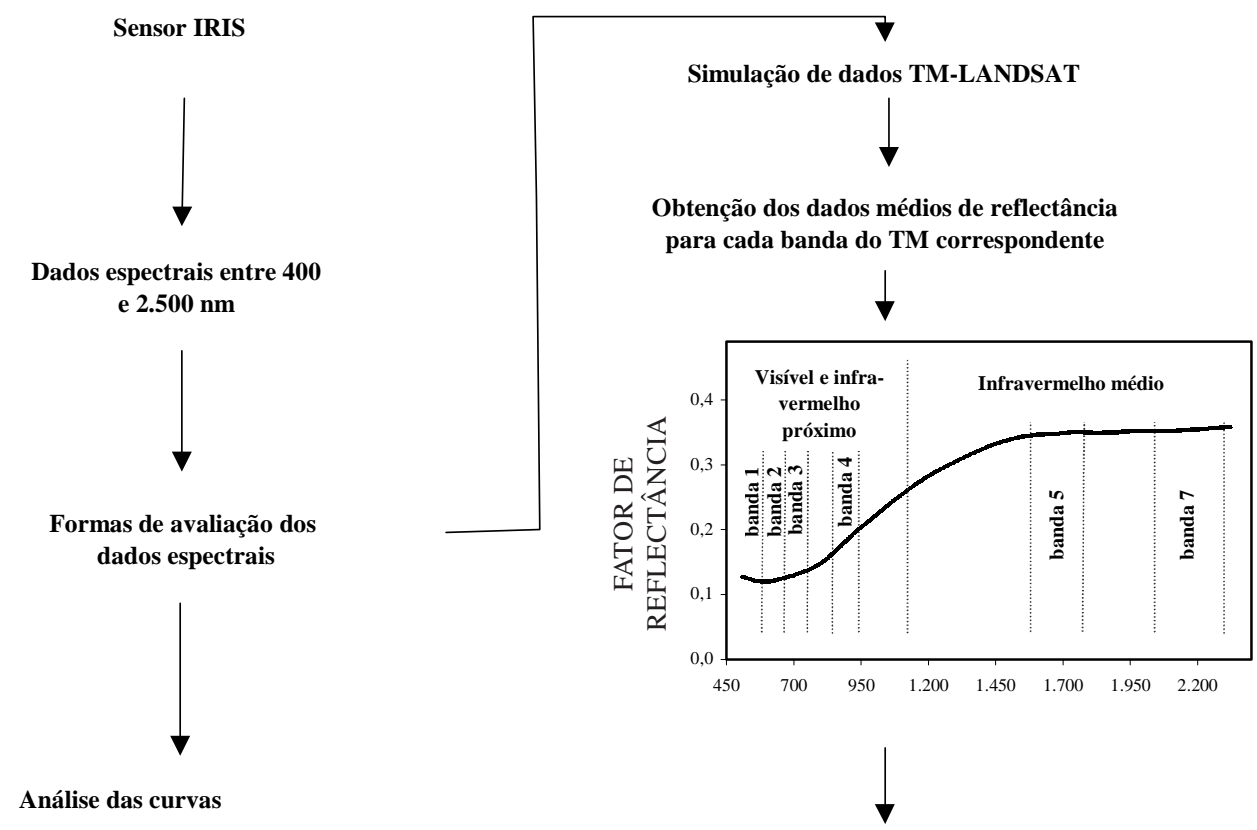

Obtenção de novo gráfico simulando o TM
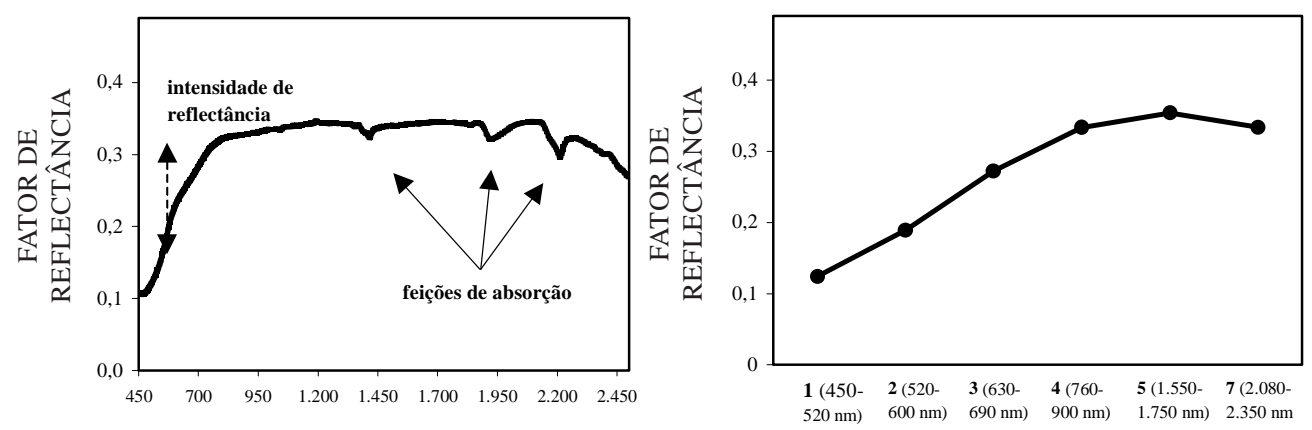

COMPRIMENTO DE ONDA, nm

Figura 1. Obtenção das curvas espectrais pelo Sensor IRIS e si mulação do TM-Landsat-5. 
A aval iação descritiva das curvas espectrais foi realizada de acordo com Stoner \& Baumgardner (1981), sendo os tipos de curvas por eles estabel eci dos também discutidos em Valeriano et al. (1995) e Formaggio et al. (1996). Além disso, foram avaliadas as feições de absorção e a intensidade do fator de reflectância (Figura 1). A simulação dos dados do Landsat 5 TM foi determi nada pel o cál cul o da média dos valores de reflectância obtidos nos intervalos espectrais das bandas do TM (nm), ou seja, banda 1 (450-520), 2 $(520-600), 3$ (630-690), 4 (760-900), 5 (1.550$1.750), 7$ (2.080-2.350), possibilitando a comparação dos dados terrestres com orbitais.

A imagem orbital, órbita-ponto 220-76 com data de passagem de setembro de 1992, foi processada a fim de corrigir as interferências atmosféricas e obter os valores de reflectância para a construção das curvas espectrais dos sol os. Decada uma das bandas da imagem, foram extraídos, pixel a pixel, os valores de reflectância no topo da atmosfera e, em seguida, foi aplicado o modelo 6S para a correção do espalhamento Rayleigh e absorção do ozônio. As equações mostradas abaixo estão descritas com maior detal he por Tanré et al. (1992) e por Vermont et al. (1995):

$$
\begin{gathered}
L_{S(\lambda)}=n_{I}+m_{1} * D N_{\lambda} \\
\rho_{a p p}=\frac{\pi * L_{S \lambda}}{E_{o, \lambda}} \Rightarrow \frac{\pi * d^{2} * L_{S \lambda}}{E_{o, \lambda} * \cos \left(\theta_{z}\right)} \\
\rho^{*}=\frac{\frac{\rho_{a p p}}{t_{o 3}}-\rho_{a, r}}{T_{r}}
\end{gathered}
$$

em que $L_{s(\lambda)}\left(W m^{-2} s r^{-1} \mu m^{-1}\right)$ é a radiância no sensor; $D N(\lambda)$ é o número digital para uma faixa de TM; n, m são os coeficientes de calibração do sensor TM; $\rho_{\text {app }}$ é a reflectância aparente no "topo da atmosfera"; $\mathrm{E}_{\text {ò }}$ éa irradiância exo-atmosférica solar relacionada com cada banda espectral do TM; $\theta z$ éo ângulo de el evação solar; d éa distância da Terra-Sol (unidade astronômica); $\rho^{*}$ é a relação Rayleigh/Ozone (reflectância corrigida); $t_{03}$ é a transmitância do ozônio; $\rho_{a}$ r é o espalhamento Rayleigh atmosférico; $T_{r}$ é a absorção atmosférica Rayleigh total.

Posteriormente, em cada área-teste, foram amostrados os dados de reflectância de cada solo, sendo 17 pixels amostrados para o LR e 18 para a RQ e para o PV. A escol ha dos pixels para as amostragens partiu da determinação das áreas com solo exposto. Para isso, foi realizado um gráfico da dispersão (scatter plot) dos valores de reflectância das bandas 4 e 3, representando a linha do solo (Baret et al., 1993). Este gráfico apresentou um conjunto de pontos que refletem a relação entre estas duas bandas para todos os pixels da imagem. No gráfico, foram marcados todos os pontos próximos à linha $1: 1$, apresentando cada ponto um pixel da imagem. Quanto mais próximo da linha 1:1, maior a possibilidade de o pixel representar sol o exposto. Após marcar os pontos no gráfico, foi possível visualizar os pixels que indicam solo exposto. Além disso, analisou-se a percentagem de cobertura do solo pelo índice de vegetação "Soil Adjust Vegetation Index" (SAVI), Huete (1989). Quando o valor do índice SAVI para determinado pixel fosse igual a zero, considerou-se como um indicativo de solo exposto, sem vegetação, portanto:

$$
S A V I=\left[\frac{I V P-V}{(I V P+V+0,5)}\right] * 1,5
$$

em que IVP é a reflectância na faixa do infravermelho (banda 4 do Landsat 5 TM) eV éa reflectância na faixa do vermelho (banda 3 ).

Numa segunda etapa, em cada ponto marcado pelo scatter plot foi avaliada a posição do pixel em relação aos limites do solo na Quadrícula do levantamento Semidetalhado de Solos de Piracicaba, buscando-se os pixels localizados no interior das unidades de mapeamento estudadas. Para isto, foi sobreposto sobre a imagem o mapa da quadrícula previamente digitalizado. Avaliouse também a posição dos pixels com solo exposto em relação ao rel evo.

A análise visual da imagem também contribuiu para a identificação das áreas com solo exposto. Foram usadas duas composições RGB, das bandas 5,4 e 3 , e 3,2 e 1 . Portanto, o ponto de amostragem só era considerado satisfatório se atendesse a todos os fatores anteriormente citados, conforme estabelecido por Demattê et al . (2000).

A classificação digital dos solos baseou-se nos pixels coletados para a obtenção das curvas espectrais. Os pixels col etados para o cál culo da média da reflectância foram utilizados como amostras de treinamento no classificador "Spectral Angle Mapper" (SAM), baseado em pixels puros, conforme previamente descritos para as áreas-base, ereferentes aos locais previamente avaliados pela radiometria em condições de laboratório (padrão).

Posteriormente, foram escol hi das áreas-teste, onde se realizou a classificação digital, utilizando os dados da área-base, sendo anal isados os pontos com índice de vegetação zero e com níveis de reflectância iguais aos da linha dos solos, obtidos na área-base, configurando áreas de sol o exposto. A classificação usando o classificador SAM foi realizada no software ENVI com seis classes: água, vegetação, área urbana, LR, PV e RQ. A 
Área de estudo

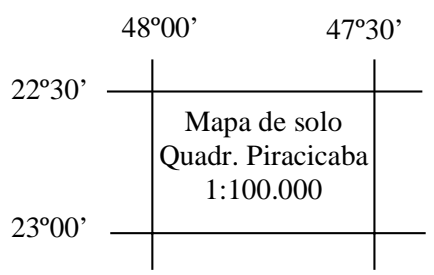

Áreas-base (classes de solo)

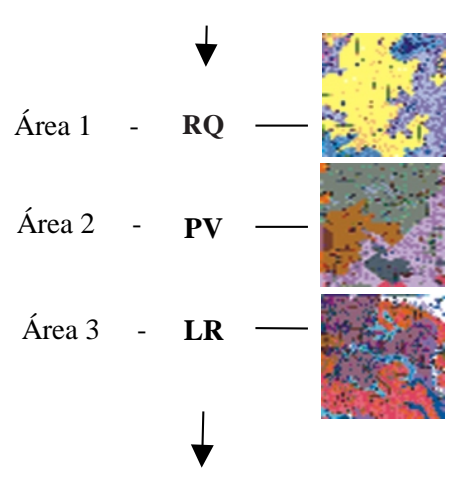

Amostras de solos (coletas no campo)

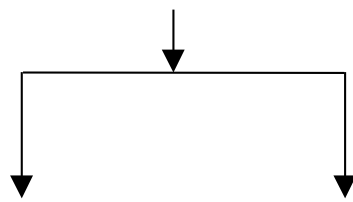

Espectrorradiometria Análise laboratorial em laboratório físico-química
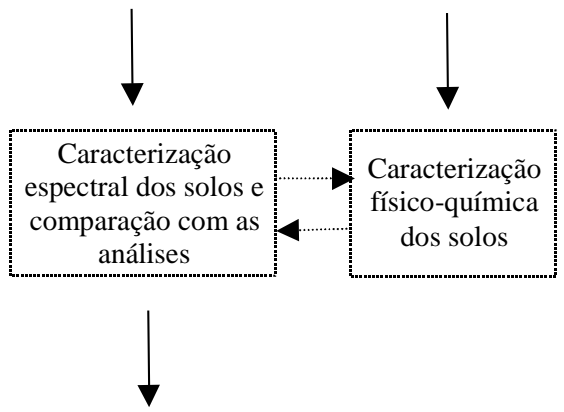

Base para escolha dos pontos de amostragem na imagem digital

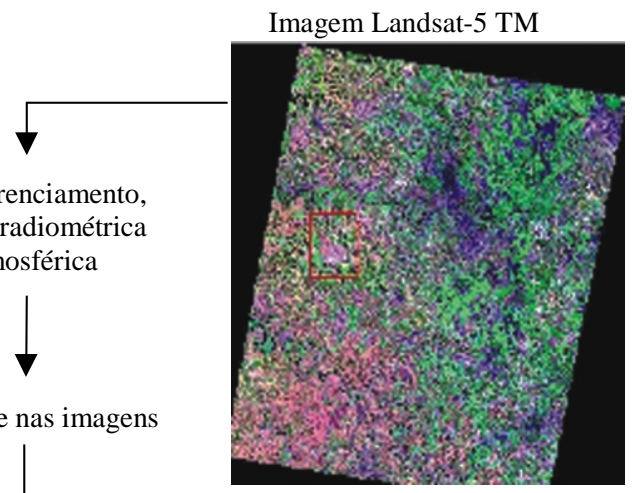

Determinação da

linha dos solos e interpretação

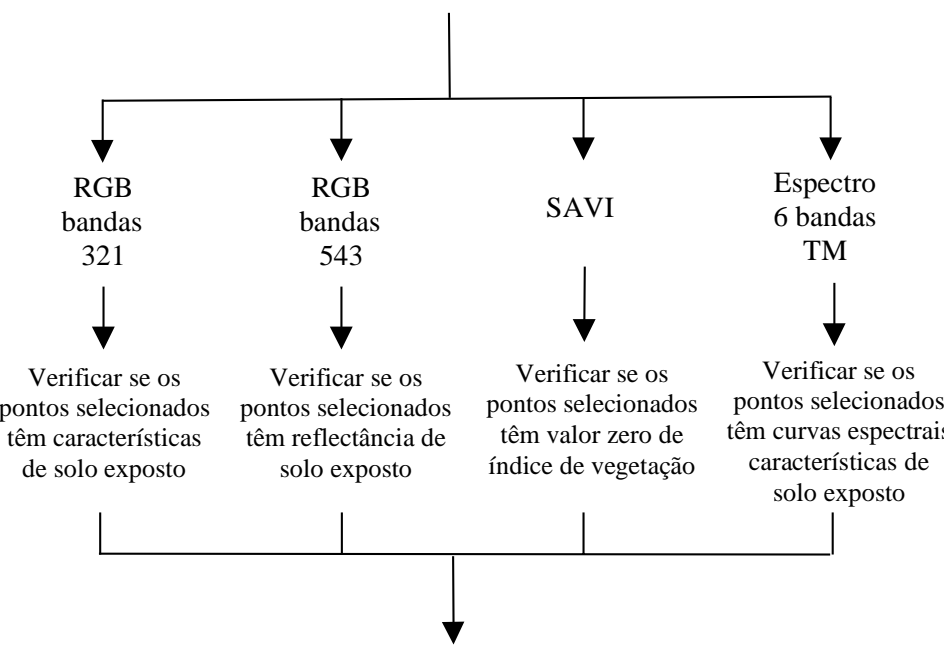

Todos fatores satisfeitos $\cong$ solo exposto

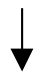

Amostras de treinamento para a classificação na imagem (30 pontos selecionados para cada classe de solo)

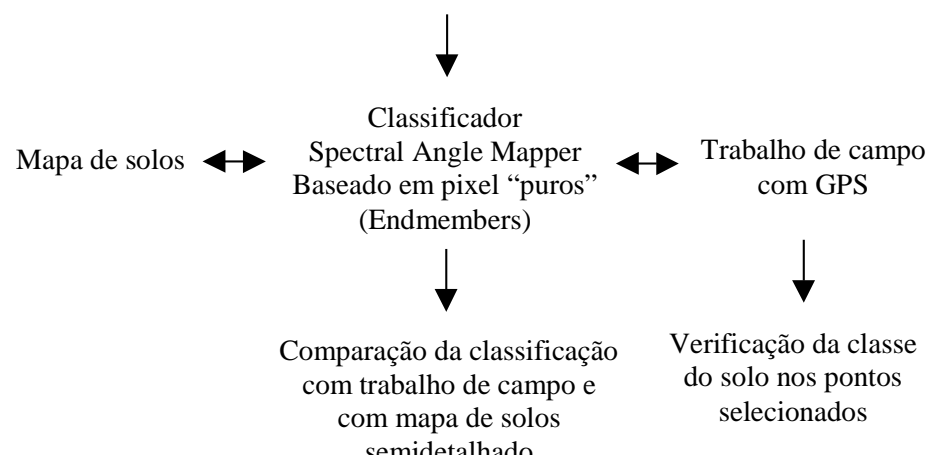

Figura 2. Fluxograma das atividades desenvolvidas.

probabilidade utilizada para a classificação foi de $95 \%$. A pós esta etapa, foram realizadas checagens de campo, com apoio do mapa de sol os e GPS, com o propósito de avaliar o resultado da distribuição espacial das classes selecionadas na classificação e confrontá-lo com o mapa semidetal hado de solos da região. As figuras 2 e 3 ilustram a seqüência de trabalho. 

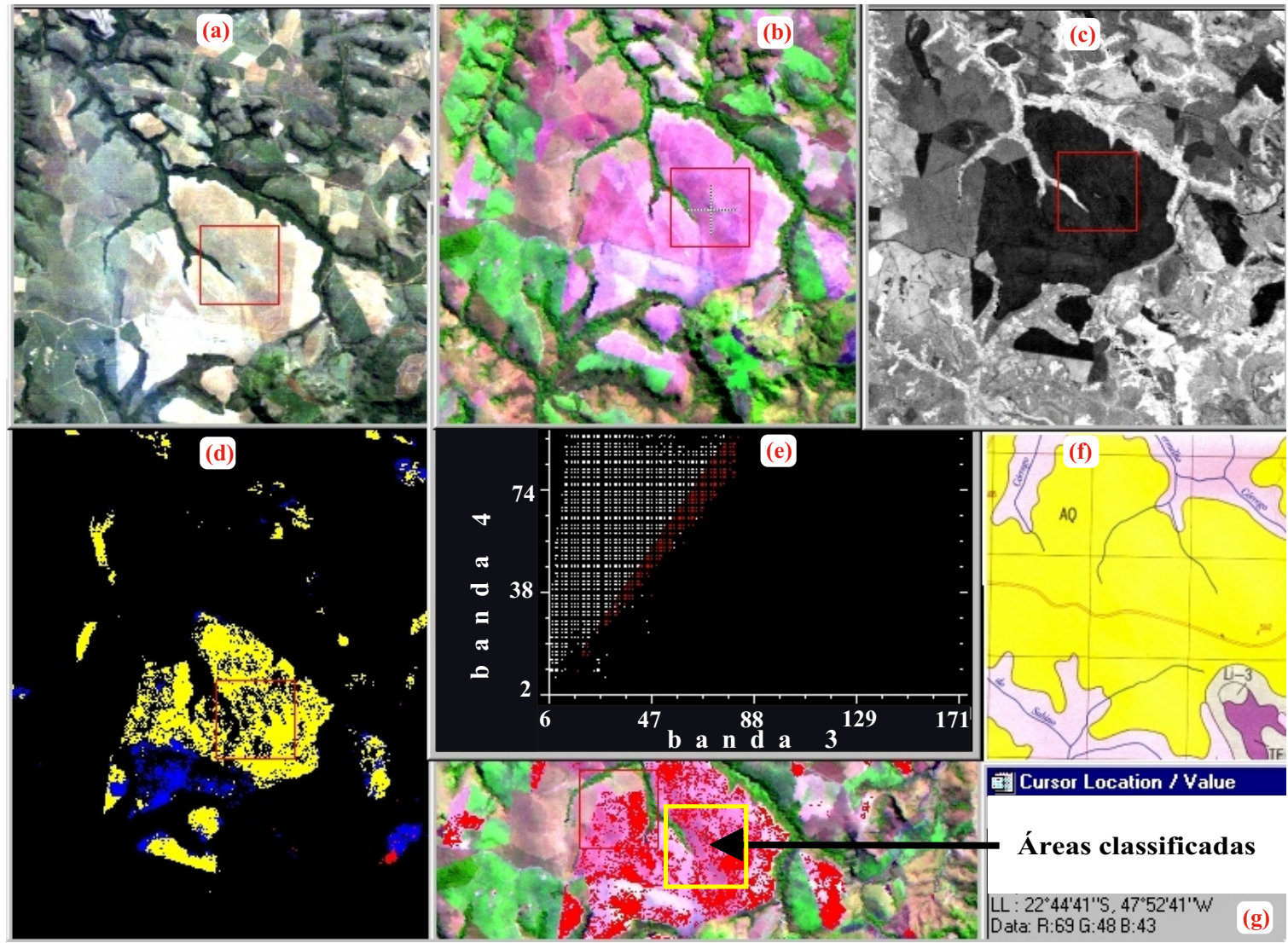

Figura 3. Ilustração da metodologia: (a) Composição 3R, 2G, 1B; (b) Composição 5R, 4G, 3B; (c) I magem do índice de vegetação SAVI; (d) I magem classificada discrimi nando as classes de solo (RQ-amarelo; PV-azul; LR-vermelho); (e) Gráfico com a dispersão da reflectância relacionada com as bandas 4 e 3 (pontos a 45 graus no gráfico são relativos à Linha do Solo) e imagem com pixels marcados (vermelho) indicando solo exposto. (f) Limites do mapa de solos. (g) Coordenadas do ponto indicado pelo cursor e posteriormente localizados no campo.

\section{RESULTADOS E DISCUSSÃO}

\section{Caracterização espectral dos solos (laboratorial e orbital)}

As três classes encontram-se na região geomorfológica denominada Depressão Periférica. Observam-se, pel as características físicas e químicas (Quadro 1), três solos, cujos atributos também são analisados estatisticamente quanto aos teores de matéria orgânica, óxidos de Fe, areia, silte, argila, $\mathrm{Ca}^{2+}$ eV \% (Quadro 2).

O Latossolo Roxo, LR (Latossolo Vermel ho distroférrico) teve um padrão espectral semel hante ao da curva a pertencente à mesma classe de sol os no estudo deF ormaggio et al. (1996) (Figura 4). Seu comportamento é resultado basicamente dos altos teores de óxidos de $\mathrm{Fe}\left(186,46 \mathrm{~g} \mathrm{~kg}^{-1} \mathrm{Fe}_{2} \mathrm{O}_{3}\right), \mathrm{MnO}$ e $\mathrm{TiO}_{2}$ diferenciando-se estatisticamente dos outros solos. O alto teor de hematita e o elevado teor de argila resultam em solos com baixo al bedo, ou seja, reflectância baixa na faixa do visível einfravermel ho, e mascaram as feições de absorção da água e dos outros minerais. O baixo al bedo étambém resultado da presença de minerais opacos, como a ilmenita ea magnetita, expressos pelos teores de $\mathrm{TiO}_{2}$ e $\mathrm{MnO}$. Algumas bandas de absorção perceptíveis nesta classe de solo estão presentes entre 450 e $550 \mathrm{~nm}$ e entre 800 e $950 \mathrm{~nm}$ devido à presença de $\mathrm{Fe}^{3+}$.

O Podzólico Vermelho-Amarelo, PV (Argissolo Vermel ho-Amarelo), teve um comportamento bastante si milar ao apresentado por Formaggio et al . (1996) na curva d, referentea um Podzólico VermelhoEscuro. Tais solos são caracterizados por um comportamento composto, ou seja, apresentam-se semel hantes as curvas dos LR (curvas do tipo a) na faixa de 450 a $1.100 \mathrm{~nm}$ e um comportamento mais parecido com o tipo b de curvas dos PV na faixa de 1.100 a $2.450 \mathrm{~nm}$. Seu comportamento é semel hante ao da curva do tipo a, em decorrência da influência dos óxidos de Fe presentes em teores consideráveis no solo nesta faixa do espectro (Galvão \& Vitorello, 1997). Na faixa seguinte, ocompor-tamentoéparecido com o da curva do tipo b, pelas presença de materiais 
Quadro 1. Características físicas e químicas da camada de 0-20 cm dos três solos estudados

\begin{tabular}{|c|c|c|c|c|c|c|c|c|c|c|c|c|c|c|}
\hline Solo & $\begin{array}{c}\mathbf{p H} \\
\mathrm{CaCl}_{2}\end{array}$ & $\mathbf{P}$ & $\mathbf{K}$ & $\mathbf{M g}^{2+}$ & $\mathrm{Al}^{3+}$ & $\mathbf{H}$ & SB & $\mathbf{T}$ & $\mathbf{m}$ & Cor Munsell & $\mathrm{SiO}_{2}$ & $\mathbf{A l}_{2} \mathbf{O}_{3}$ & $\mathrm{TiO}_{2}$ & MnO \\
\hline & & $\mathrm{mg} \mathrm{kg}^{-1}$ & & 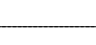 & $\mathrm{mm}$ & $\mathrm{I}_{\mathrm{c}} \mathrm{kg}^{1}$ & & - & $\%$ & & 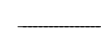 & $\mathrm{gk}$ & -1 & 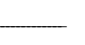 \\
\hline LR & 4,6 & 21,2 & 4,3 & 10,0 & 3,0 & 47,0 & 36,3 & 83,7 & 12,0 & $2.5 Y R \quad 4 / 2$ & 164,8 & 166,6 & 40,6 & 1,0 \\
\hline PV & 4,2 & 3,4 & 2,7 & 6,0 & 13,0 & 40,0 & 21,7 & 62,2 & 36,0 & 7.5 YR 4/4 & 122,4 & 108,3 & 14,0 & 0,4 \\
\hline RQ & 5,0 & 59,6 & 0,7 & 4,0 & 0,4 & 18,0 & 21,8 & 39,8 & 3,0 & $5 Y R \quad 3 / 4$ & 31,0 & 30,0 & 7,8 & 0,1 \\
\hline
\end{tabular}

Quadro 2. Análise estatística das propriedades físi cas e químicas de amostras de três solos na profundidade de $0-20 \mathrm{~cm}$

\begin{tabular}{|c|c|c|c|c|c|c|c|}
\hline Solo(1) & Média & $\mathbf{t}^{*}$ & $\sigma$ & Solo & Média & $\mathbf{t}^{*}$ & $\sigma$ \\
\hline \multicolumn{4}{|c|}{$\mathrm{MO}, \mathrm{g} \mathrm{kg}^{-1}$} & \multicolumn{4}{|c|}{$\mathrm{Ca}^{2+}, \mathrm{mmol}_{\mathrm{c}} \mathrm{kg}^{-1}$} \\
\hline $\begin{array}{l}\text { LR } \\
P V \\
\text { RQ }\end{array}$ & $\begin{array}{l}31,2 \\
20,6 \\
11,2\end{array}$ & $\begin{array}{l}a \\
b \\
c\end{array}$ & $\begin{array}{l}4,97 \\
3,21 \\
4,44\end{array}$ & $\begin{array}{l}\text { LR } \\
P V \\
R Q\end{array}$ & $\begin{array}{l}21,6 \\
13,0 \\
17,2\end{array}$ & $\begin{array}{l}a \\
a \\
a\end{array}$ & $\begin{array}{r}10,80 \\
5,61 \\
10,85\end{array}$ \\
\hline \multicolumn{5}{|c|}{ V (\%) } & \multicolumn{3}{|c|}{$\mathrm{Fe}_{2} \mathrm{O}\left(\mathrm{g} \mathrm{kg}^{-1}\right)$} \\
\hline $\begin{array}{l}\text { LR } \\
P V \\
R Q\end{array}$ & $\begin{array}{l}41,4 \\
34,6 \\
54,8\end{array}$ & $\begin{array}{l}a \\
a \\
a\end{array}$ & $\begin{array}{l}14,33 \\
10,33 \\
23,80\end{array}$ & $\begin{array}{l}L R \\
P V \\
R Q\end{array}$ & $\begin{array}{c}186,46 \\
3,8 \\
11,5\end{array}$ & $\begin{array}{l}a \\
b \\
b\end{array}$ & $\begin{array}{r}19,83 \\
1,03 \\
6,01\end{array}$ \\
\hline \multicolumn{5}{|c|}{ Areia $\left(\mathrm{g} \mathrm{kg}^{-1}\right)$} & \multicolumn{3}{|c|}{ Silte $\left(\mathrm{g} \mathrm{kg}^{-1}\right)$} \\
\hline $\begin{array}{l}\text { LR } \\
\text { PV } \\
\text { RQ }\end{array}$ & $\begin{array}{l}112 \\
290 \\
840\end{array}$ & $\begin{array}{l}a \\
b \\
c\end{array}$ & $\begin{array}{l}31,14 \\
58,31 \\
37,42\end{array}$ & $\begin{array}{l}\text { LR } \\
P V \\
R Q\end{array}$ & $\begin{array}{r}128 \\
282 \\
64\end{array}$ & $\begin{array}{l}a \\
b \\
c\end{array}$ & $\begin{array}{r}8,37 \\
83,19 \\
26,08\end{array}$ \\
\hline \multicolumn{5}{|c|}{ Argila $\left(\mathrm{g} \mathrm{kg}^{-1}\right)$} & \multicolumn{3}{|c|}{$\mathrm{Ki}$} \\
\hline $\begin{array}{l}\text { LR } \\
\text { PV } \\
\text { RQ }\end{array}$ & $\begin{array}{r}760 \\
428 \\
96\end{array}$ & $\begin{array}{l}a \\
b \\
c\end{array}$ & $\begin{array}{l}29,15 \\
71,55 \\
21,91\end{array}$ & $\begin{array}{l}\text { LR } \\
P V \\
\text { RQ }\end{array}$ & $\begin{array}{l}1,42 \\
1,92 \\
1,79\end{array}$ & $\begin{array}{l}a \\
a \\
a\end{array}$ & $\begin{array}{l}0,13 \\
0,33 \\
0,49\end{array}$ \\
\hline
\end{tabular}

(1) Foram anlisadas cinco amostras de cada classe de solo, na profundidade de $0-20 \mathrm{~cm}$. $\sigma$ Desvio-padrão. * teste de Tukey a 0,05 significância.

mais refletivos, como o quartzo, provenientes de materiais arenosos ou siltosos. Tal observação concorda com as deWhiteet al. (1997) queverificaram a refletividade do quartzo. A banda em $1.400 \mathrm{~nm}$ é devida aos grupos $\mathrm{OH}$ e às vibrações das moléculas de água, enquanto em $1.900 \mathrm{~nm}$ é devida à água. A feição da caulinita pode ser visualizada nas três curvas, em $2.200 \mathrm{~nm}$, porém é mais perceptível nas curvas do PV e da RQ, e menos no LR graças ao $\mathrm{Fe}_{2} \mathrm{O}_{3}$ e magnetita, componentes do solo que mascaram as feições da água e da caulinita.

Nota-se que as amostras de RQ mostraram comportamento semel hanteao da curva b (Figura 4). $\mathrm{O}$ alto al bedo apresentado por este sol o é resultado, dentre outros fatores, do baixo teor de óxidos de Fe, dos minerais opacos e do material de origem arenoso. Este solo apresenta bandas de absor ção em 1.450 e $1.950 \mathrm{~nm}$ mais visíveis em virtude da menor ocorrência de minerais opacos, mascarando estetipo de feição, assim como nas curvas do tipo d de F ormaggio et al. (1996).

As curvas espectrais dos sol os ea simulação das bandas do Landsat 5 TM mostraram o mesmo padrão de reflectância, porém com menor grau de detal he espectral das bandas de absorção presentes nas curvas obtidas em laboratório (Figura 5a). A variação na intensidade é devida ao valor médio representativo da reflectância de cada banda no gráfico simulando o Landsat $5 \mathrm{TM}$. O padrão geral dos solos foi o mesmo, aliás, em acordo com observações de Demattêet al . (2000) para os mesmos solos ocorrentes em Lençóis Paulistas. O LR apresentou o menor al bedo em todas as bandas nas três classes estudadas. Nas bandas do visível (bandas 1, 2 e 3), tal fato está associado à presença de óxidos de $\mathrm{Fe}$, como descrito anteriormente, e concordando com Galvão \& Vitorello (1998). Na curva como um todo, os minerais que absorvem 
muita energia como o $\mathrm{TiO}_{2}$ e $\mathrm{MnO}$ também atuam deforma a diminuir o fator de reflectância. A curva do PV apresentou alto albedo, mostrando que a ausência de óxidos de Fe e materiais opacos alterou a intensidade de reflectância dos solos, principalmente nas bandas do infravermelho (bandas 4, 5 e 7).

Nas imagens de satélite(Figura $5 b$ ), a intensidade de reflectância foi menor em relação ao laboratório, resultado das interferências atmosféricas, em concordância com Nanni \& Demattê (2000) para solos da região de Rafard, SP. Tais interferências foram, teoricamente, eliminadas pelo 6S. No entanto, é importante considerar outras fontes de variação, tais como: a fonte de iluminação, a heterogeneidade dos alvos, a unidade de geometria angular de visada ea iluminação. Demaneira geral, a tendência das curvas em laboratório e orbital foi semel hante. Todavia, al gumas diferenças ocorreram. A curva da RQ, que apresentava um comportamento

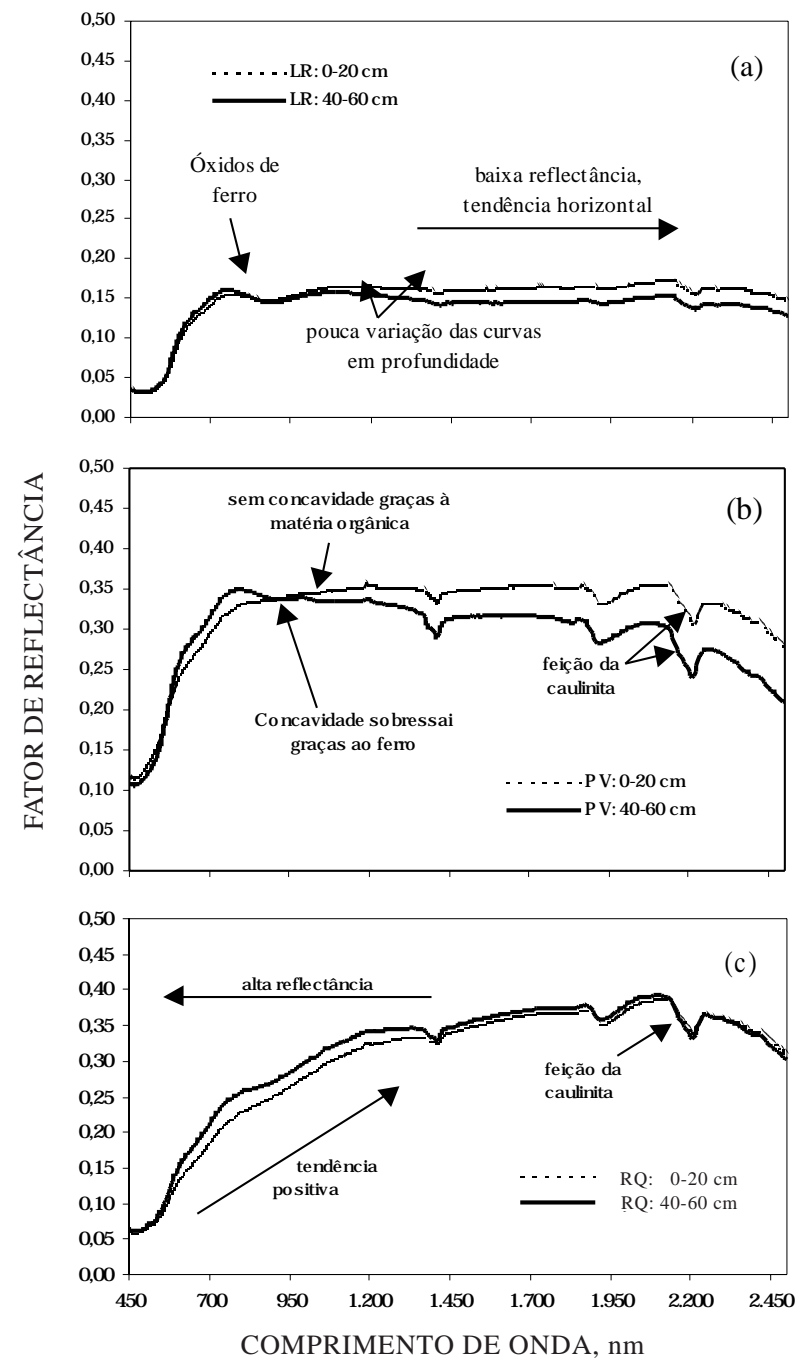

Figura 4. Dados espectrais de laboratório das amostras do Latossolo Roxo, LR (a), Podzólico Vermelho-Amarelo, PV (b) e Areia Quartzosa, RQ (c), nas profundidades de 0-20 e 40-60 cm. intermediário entre os LR e os PV nas curvas em laboratório, passou a ter maior intensidade entreas curvas orbitais. O padrão apresentado pela curva do LR nos dois níveis de aquisição se manteve, apresentando baixa intensidade eal bedo menor nas duas primeiras bandas em virtude das feições de absorção dos óxidos deFe. As bandas 4, 5 e 7 tendiam a um ascendente, ao contrário dos valores orbitais. Tais resultados concordam com os de Nanni \& Demattê (2000) e se devem a aspectos de umidade das amostras decampo, que di mi nuem a intensidade de energia refletida. Fato semel hante ocorreu com oPV.

\section{Correlação dos atributos do solo com as bandas do Landsat 5 TM}

Foram determinadas correlações entre os atributos do solo e as bandas 1, 2, 3, 4, 5 e 7 simuladas em laboratório referentes às faixas espectrais do TM (Quadro 3). Valores acima de 0,7 indicam que houve boa correlação. Os resultados mais satisfatórios podem ser observados nas bandas do infravermelho (4, 5 e 7), relacionados com el ementos estruturais do solo, como: areia, silte, argila, $\mathrm{Fe}_{2} \mathrm{O}_{3}, \mathrm{Al}_{2} \mathrm{O}_{3}, \mathrm{TiO}_{2}$ e $\mathrm{MnO}$ e com a matéria orgânica, concordando com Ben-Dor \& Banin (1995). Os val ores obtidos para areia mostraram correlação

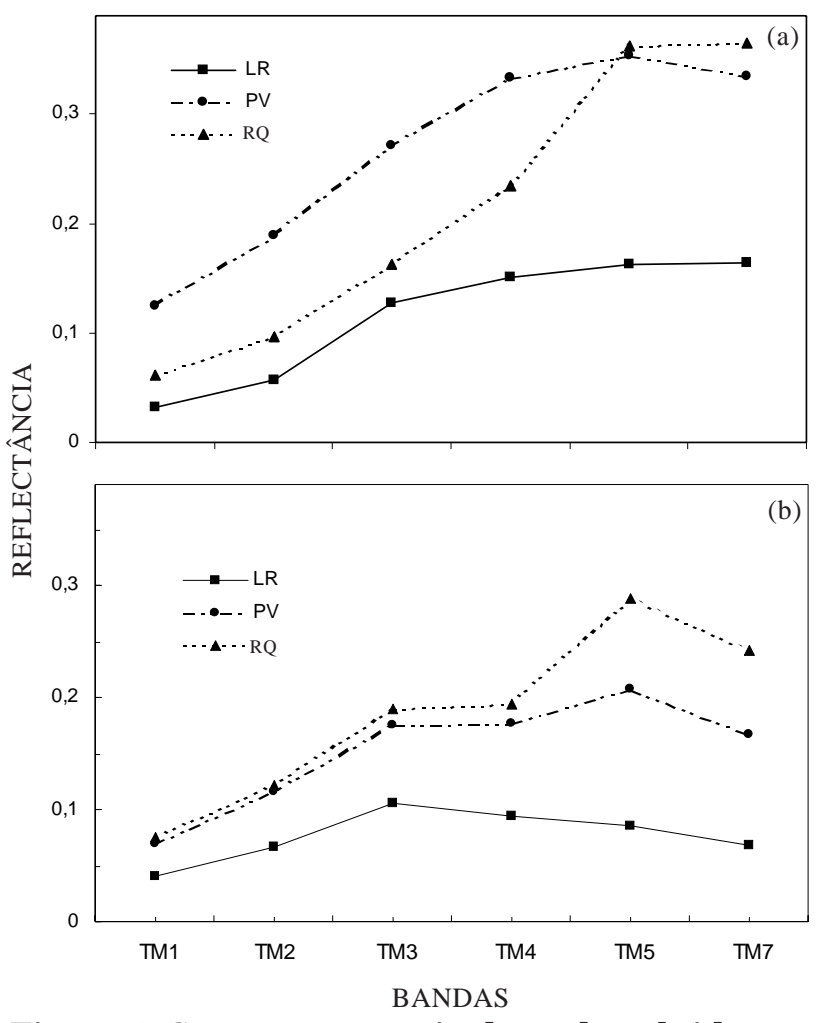

Figura 5. Curvas espectrais dos solos obtidas em laboratório, si mulando as bandas do Landsat 5TM (a) e curvas espectrais dos solos obtidas de dados do Landsat 5-TM(b). 
positiva em quase todo o espectro, fato ratificado na literatura (Demattê et al., 2000) e nas curvas observadas. Para o silte, verificou-se também correlação positiva, bem como o aumento da reflectância de materiais intemperizáveis, concordando com Demattê \& Garcia (1999). Acredita-se que os minerais intemperizáveis tenham maior atuação na faixa do visível, o que justifica as melhores correlações. Solos mais argilosos apresentam menor intensidade de reflectância e explica a correlação negativa referente a este atributo do solo.

As características dos elementos que compõem a fração argila (óxidos de $\mathrm{Fe}$, minerais de argila) apresentam processos vibracionais que absorvem energia. Tais elementos encontram-se em menor proporção nos sol os mais arenosos, ocorrendo efeito contrário. O mesmo pode ser observado quanto aos resultados obtidos para $\mathrm{Fe}_{2} \mathrm{O}_{3}, \mathrm{Al}_{2} \mathrm{O}_{3}, \mathrm{TiO}_{2}, \mathrm{MnO}$ e matéria orgânica, em que as maiores correlações encontram-se na TM5 e TM 7. Em particular, o Fe apresentou valores satisfatórios em quase todo o espectro, concordando com Nanni \& Demattê(2000). I sto indica que um mesmo el emento pode ter efeito em várias bandas de absorção, em menor ou maior proporção. $\mathrm{Na}$ realidade, a curva espectral é o resultado deum "jogo de forças" entre características do elemento e energia incidente e refletida. Neste aspecto, todos os el ementos dosolo atuam si multaneamente, gerando, finalmente, uma curva espectral .

\section{Avaliação da linha de solo (LS)}

A LS dos três solos obtida em laboratório (Figura 6) mostrou resultados semel hantes aos obtidos por Baret et al. (1993) e Galvão \& Vitorello (1998). As LS dos solos com menor al bedo, caso do LR, apresentaram valores de curva (a) e intercepto (b) similares aos apresentados pela literatura. I sso é resultado do baixo albedo dos solos e da interferência dos altos teores de óxidos de Fe.

É possível observar a menor dispersão dos pontos para a LS do LR, mostrando a maior homogeneidade deste sol o frenteàs outras duas classes. A LS do PV apresentou diferenças em relação à apresentada pelo $L R$, principalmente na dispersão dos dados e no maior afastamento dos pontos em relação à origem, mostrando que esta classe de solo apresenta maior intensidade de reflectância (Figuras 4 e 5), concordando com Galvão \& Vitorello (1998). É possível observar também que a inclinação da linha de solo desta classe é intermediária, resultado dos val ores também intermediários da matéria orgânica e do teor de Fe (Quadro 1).

Os dados da RQ mostraram alta dispersão e intensidade de reflectância média. A inclinação da curva também foi a maior entre os sol os, tanto para os dados de laboratório quanto para os dados orbitais. A comparação entre os níveis de aquisição de dados mostrou que a linha de solo dos dados do Landsat 5TM foi próxima às apresentadas nos dados de laboratório e que a inclinação e o intercepto das linhas de solo em ambos os níveis mostraram o mesmo comportamento entre os sol os. A semel hança na forma das curvas e dos $\mathrm{R}^{2}$ obtidos entre os dados de laboratório e orbitais é um indicativo da veracidade dos dados obtidos pelo satélite. Isso concorda com Huete (1996), que col oca os trabal hos de laboratório em alto grau de importância para o entendimento dos dados orbitais.

Por outro lado, os dados de laboratório, que representam a curva espectral real dos solos, apresentaram também $\mathrm{R}^{2}$ mais expressivos. Os dados orbitais, apesar de também apresentarem altos $R^{2}$, são mais baixos. I sso indica que os resultados orbitais, apesar de todo o cuidado metodológico, estão sendo influenciados por fatores não controlados, como restos de culturas, rugosidade da superfície, umidade, atmosfera, geometria de ângul os de visada e iluminação (Guyot, 1996).

\section{Classificação digital}

A pós a calibração dos dados orbitais dos sol os nas áreas-base, outras três áreas foram redlassificadas. Primeiramente, os pixels foram classificados pelo

Quadro 3. Coeficiente de correlação entre reflectância obtida em laboratório e atributos dos solos da camada de $0-20 \mathrm{~cm}$

\begin{tabular}{|c|c|c|c|c|c|c|}
\hline \multirow{2}{*}{ Atributo } & \multicolumn{6}{|c|}{ Banda (nm) } \\
\hline & 450 a 520 & 520 a 600 & 630 a 690 & 760 a 900 & 1550 a 1750 & 2080 a 2350 \\
\hline Matéria orgânica & $-0,351$ & $-0,337$ & $-0,284$ & $-0,464$ & $-0,758$ & $-0,799$ \\
\hline $\mathrm{Ca}^{2+}$ & $-0,499$ & $-0,502$ & $-0,551$ & $-0,599$ & $-0,591$ & $-0,569$ \\
\hline Areia & 0,017 & $-0,009$ & $-0,069$ & 0,154 & 0,575 & 0,644 \\
\hline Silte & 0,804 & 0,817 & 0,828 & 0,693 & 0,323 & 0,236 \\
\hline Argila & $-0,319$ & $-0,294$ & $-0,229$ & $-0,433$ & $-0,775$ & $-0,822$ \\
\hline $\mathrm{Fe}_{2} \mathrm{O}_{3}$ & $-0,712$ & $-0,698$ & $-0,649$ & $-0,771$ & $-0,840$ & $-0,837$ \\
\hline $\mathrm{Al}_{2} \mathrm{O}_{3}$ & $-0,375$ & $-0,346$ & $-0,274$ & $-0,464$ & $-0,798$ & $-0,839$ \\
\hline $\mathrm{TiO}_{2}$ & $-0,552$ & $-0,531$ & $-0,481$ & $-0,620$ & $-0,795$ & $-0,807$ \\
\hline $\mathrm{MnO}$ & $-0,419$ & $-0,409$ & $-0,357$ & $-0,526$ & $-0,731$ & $-0,759$ \\
\hline
\end{tabular}


sistema Endmember e, posteriormente, avaliados individualmente pelo método de Demattê et al. (2000). Ou seja, o pixel classificado pel oEndmember para ser considerado do solo RQ deveria atender às exigências para ser solo exposto - avaliado aqui de acordo com Demattêet al. (2000) (Figura 2 e 3) eter sido classificado pelo pedólogo. Se o pedólogo indicasse ser uma RQ, mas os valores digitais fossem interpretados como não sendo de solo exposto, o ponto não era considerado como RQ.

O quadro 4 apresenta os resultados das classificações na imagem, no campo e no mapa semidetalhado, para fins comparativos. Na área onde a maior ocorrência era de RQ, foram avaliados 136 locais. Destes, $91,2 \%$ foram identificados como RQ no campo. Os mesmos locais, identificados por
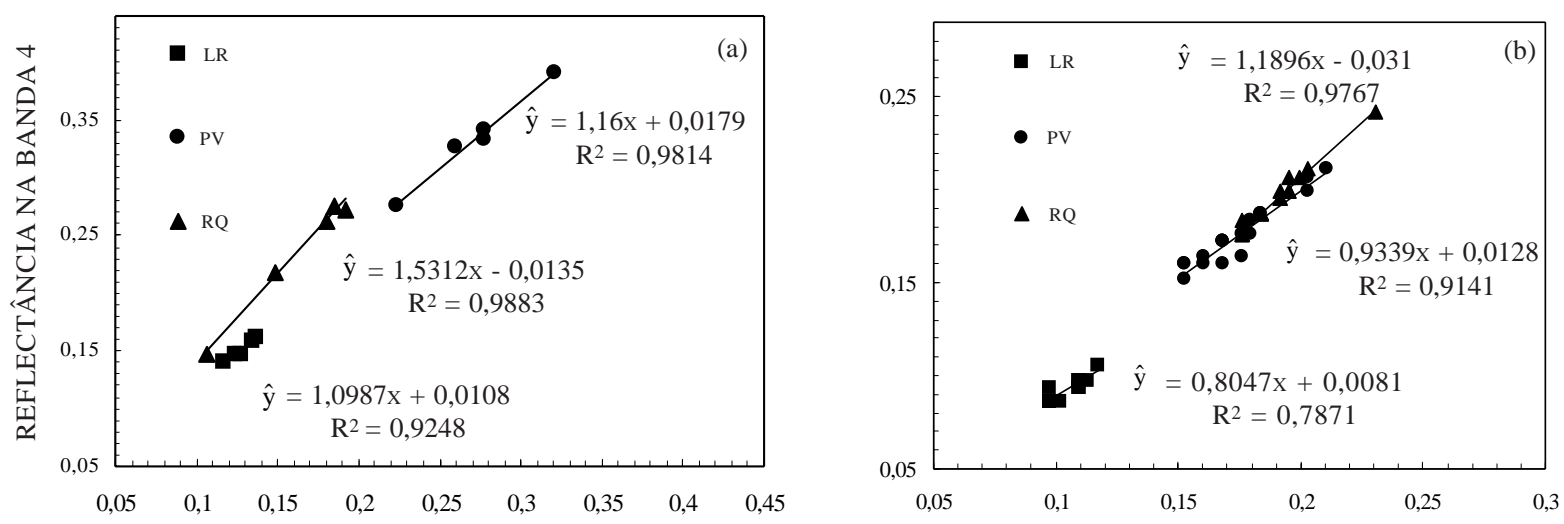

REFLECTÂNCIA NA BANDA 3

Figura 6. Linhas dos solos com dados de laboratório si mulando o TM (a) e com dados or bitais do Landsat 5TM (b).

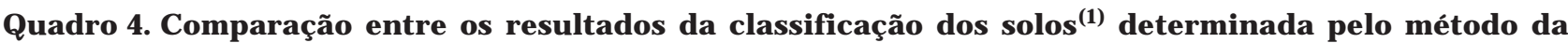
imagem, pelo mapa semidetalhado e pelas observações de campo

\begin{tabular}{|c|c|c|c|c|c|}
\hline \multirow{2}{*}{$\begin{array}{l}\text { Número de } \\
\text { observação }\end{array}$} & \multicolumn{3}{|c|}{ Classificação do solo } & \multicolumn{2}{|c|}{ Coincidência } \\
\hline & $\begin{array}{c}\text { Metodologia pela } \\
\text { imagem }\end{array}$ & $\begin{array}{l}\text { No mapa de solo } \\
\text { semidetalhado }\end{array}$ & $\begin{array}{c}\text { No } \\
\text { campo }\end{array}$ & $\begin{array}{l}\text { Imagem } \\
\text { vs Campo }\end{array}$ & $\begin{array}{c}\text { Semidetalhado } \\
\text { vs Campo }\end{array}$ \\
\hline $\begin{array}{c}77 \\
47 \\
12 \\
\text { Total: } 136\end{array}$ & Área & $\begin{array}{l}\text { edominância de RQ } \\
\text { RQ } \\
\text { RQ } \\
\text { PV + Li }\end{array}$ & $\begin{array}{l}\text { RQ } \\
\text { RQ } \\
\text { PV }\end{array}$ & 65,4 & $\% \frac{}{91,2}$ \\
\hline $\begin{array}{c}47 \\
39 \\
6 \\
30 \\
8 \\
\text { Total: } 130\end{array}$ & $\begin{array}{l}\text { PV } \\
\text { PV } \\
\text { PV } \\
\text { RQ } \\
\text { RQ }\end{array}$ & $\begin{array}{c}\text { edominância de PV } \\
L i+P V \\
P V \\
L i+P V \\
L i+P V \\
L i+P V\end{array}$ & $\begin{array}{l}\text { PV } \\
\text { PV } \\
\text { PV } \\
\text { PV } \\
\mathrm{Li}\end{array}$ & 70,8 & 100,0 \\
\hline $\begin{array}{r}88 \\
17 \\
7 \\
18 \\
3 \\
\text { Total. } 133\end{array}$ & $\begin{array}{l}\text { LR } \\
\text { PV } \\
\text { PV } \\
\text { LR } \\
\text { PV }\end{array}$ & $\begin{array}{l}\text { edominância de LR } \\
\text { LR } \\
\text { LR } \\
\text { LR } \\
\text { G1 } \\
\text { G1 }\end{array}$ & $\begin{array}{l}\text { LR } \\
\text { LR } \\
\text { PV } \\
\text { LR } \\
\text { LR }\end{array}$ & 85,0 & 78,9 \\
\hline
\end{tabular}

(1) Classificação de acordo com Camargo et al. (1987) para fins comparativos, sendo: LR, Latossolo Roxo distrófico A moderado textura muito argilosa ou argilosa (Latossolo Vermelho distroférrico, Typic Haplorthox), Formação Serra Geral - basalto, arenito inter-trap, diabásio; PV, grupamento indiscriminado de Podzólicos Vermelho-Amarel os Tb abruptos A moderado textura arenosa/ argi losa ou média/argil osa (Abruptic Paleudalf, Abruptic Arenic Paleudalf, Abruptic Paleudult eAbruptic Arenic Paleudult, Argissolo Vermelho), Grupo Tubarão - arenitos, siltitos, varvitos, tilitos, conglomerados e fósseis; RQ, Areia Quartzosa álica profunda e pouco profunda A moderado (Typic Quartzipsamment, Neossolo Quartzarênico); Li-2-Solo Litólico eutrófico ou distrófico A moderado proeminente ou chernozêmico textura média substrato sedimentos indiscriminados do Grupo Tubarão. Neossolo Litólico, Typic Udorthent). 
georreferenciamento no mapa semidetalhado da região, indicaram também todos como RQ. Nesse caso, o mapa semi detal hado obteve $100 \%$ de acerto com o que foi visto no campo. Dentro da unidade de mapeamento tipo associação, identificada como PV + Li no mapa, foram identificados $8,8 \%$ de PV no campo, também concordando com as informações do mapa. Na área de ocorrência de Podzólicos também houve concordância entre o campo eo mapa. A única diferença é que o campo indica a avaliação pontual eo mapa uma unidade de mapeamento. No caso da área dos $L R$, porém, 5,3\% das amostragens indicaram ocorrência de PV no campo, sendo LR no mapa. Esses "erros" são inerentes ao detal hamento do mapa.

Posteriormente, foi avaliada a classificação por imagens de satélite com o mapa semidetal hado (Quadro 4). Observou-se que $56,6 \%$ dos pixels classificados como RQ estavam dentro da unidade de mapeamento RQ do mapa, havendo, portanto, coincidência. Entretanto, 34,6 \% das amostragens foram identificadas como PV pela imagem, sendo RQ no mapa. Nesse caso, as checagens de campo é quetiraram a dúvida, demonstrando ser RQ. Apesar disso, 8,8 \% dos Podzólicos foram coincidentes entre campo e imagem. A confusão da classificação pela imagem é explicada por referir a leitura espectral à camada superficial e, no caso, são PV arenosos. A imagem não tem como avaliar o horizonte $B$ diagnóstico, demonstrando sua limitação. $\mathrm{Na}$ área de predominância de PV, houve $70,8 \%$ de coincidência entre a classificação das imagens e no campo. $\mathrm{Na}$ área-teste com predominância de LR $85,0 \%$ das amostragens foram coincidentes entre campo e imagem.

\section{CONCLUSÕES}

1. Os solos estudados podem ser caracterizados ediscriminados pel o sensoriamento remoto espectral em laboratório e em nível orbital.

2. Os elementos estruturais que mais influenciaram o comportamento espectral dos solos foram: argila, $\mathrm{Fe}_{2} \mathrm{Al}_{2} \mathrm{O}_{3}, \mathrm{TiO}_{2}, \mathrm{MnO}$ eareia.

3. Os dados espectrais de laboratório foram mais eficientes no diagnóstico das interações entre os atributos dos solos ea reflectância. Além disso, estes dados foram fundamentais como base metodológica para o reconhecimento do nível orbital.

4. O método proposto indica que podem-se ser utilizados dados orbitais no reconhecimento de sol os nos níveis: pontual (local específico no campo) e espacial (unidade de mapeamento) com até $85 \%$ de confiabilidade. Esta técnica pode auxiliar, portanto, em mapeamentos de solos, principalmente no nível semidetalhado.

\section{AGRADECIMENTOS}

À F undação de Amparo à Pesquisa, do estado de São Paulo, pela aquisição do espectrorradiômetro IRIS (proc. n. 95/6259-6), eao Consel ho Nacional de Pesquisa e Desenvolvimento, pela bolsa de pesquisador do primeiro autor.

\section{LITE RATURA CITADA}

BARET, F.; J ACQUEMOUD, S. \& HANOCQ, J .F. The soil line concept in remote sensing. Remote Sens. Environ., 7:1-18, 1993.

BEN-DOR, E. Quantitative remote sensing of soil properties. Adv. Agron., 75:174-243, 2002.

BEN-DOR, E. \& BANIN, A. Near Infrared analysis (NIRA) as a method to simultaneously evaluate spectral featureless constituents in Soils. Soil Sci., 159:259-269, 1995.

BRASIL. Ministério da Agricultura. Centro Nacional de Ensino e Pesquisas Agronômicas. Comissão de Solos. Levantamento de Reconhecimento de solos do Estado de São Paulo. Rio deJ aneiro, 1960. 634p. (SNPA. Boletim, 12)

CAMARGO, M.N.; KLANT, E.S. \& KAUFMAN, J.H. Classificação de sol os usada em levantamentos pedológicos no Brasil. Separata do B. Inf. Soc. Bras. Ci. do Solo, 12:1133, 1987.

CAMARGO, O.A.; MONIZ, A.C.; J ORGE, J .A. \& VALADARES, J.M. Métodos de análise química, mineralógica e física de solos do IAC. Campinas, Instituto Agronômico de Campinas, 1986. 94p. (IAC Bol etim Técnico, 106)

CIPRA, J .E.; FRANZMEIER, D.P.; BAUER, M.E. \& BOYD, R.K. Comparison of multispectral measurements from some nonvegetated soils using Landsat digital data and a spectroradiometer. Soil Sci. Soc. Am. J ., 44:80-84, 1980.

DEMATTÊ, J .A.M.\&.GARCIA, G.J . Alteration of soil properties through a weathering sequence as evaluated by spectral reflectance. Soil Sci. Soc. Am. J ., 63:327-342, 1999.

DEMATTÊ, J .A.M.; HUETE, A.R.; FERREIRA J r., L.G.; ALVES, M.C.; NANNI, M.R. \& CERRI, C.E. Evaluation of tropical soils through ground and orbital sensors. In: INTERNATIONAL CONFERENCE GEOSPATIAL INFORMATION IN AGRICULTURE AND FORESTRY, 2., Lake Buena Vista, 2000. Proceedings. Ann Arbor, 2000. v.2, p.35-42.

EMPRESA BRASILEIRA DE PESQUISA AGROPECUÁRIA EMBRAPA. Centro Nacional de Pesquisa de Sol os. Sistema brasileiro de classificação de solos. Brasília, Serviço de Produção de I nformação, 1999. 412p.

EPIPHANIO, J.C.N.; FORMAGGIO, A.R.; VALERIANO, M.M. $\&$ OLIVEIRA, J.B. Comportamento espectral de solos do Estado de São Paulo. São J osé dos Campos, INPE/MCT, 1992. 132p. 
FORMAGGIO, A.R. Comportamento espectral de quatro solos do Estado de São Paulo nos níveis orbital, de campo e de laboratório. São J osé dos Campos, Instituto Nacional de Pesquisas Espaciais, 1983. 90p. (Tese de Mestrado)

FORMAGGIO, A.R.; EPIPHANIO, J .C.N.; VALERIANO, M.M. \& OLIVEIRA, J.B. Comportamento espectral (450$2.450 \mathrm{~nm}$ ) de sol os tropicais de São Paulo. R. Bras. Ci. Solo, 20:467-474, 1996.

GALVÃO, L.S. \& VITORELLO, I. Variality of laboratory measured soil lines of soil from southeastern Brazil. Remote Sens. Environ., 6:166-181, 1998.

GALVÃO, L.S.; VITORELLO, I. \& FORMAGGIO, A.R. Relationships of spectral reflectance and color among surface and subsurface horizons of tropical soil profiles. Remote Sens. Environ., 61:24-33, 1997.

GUYOT, G.; GU, X.F.; WEISS, M \& BARET, F. Du signal satellitaire à la reflectance au sol: pròblemes direct et inverse. Photointerp., 32:119-137, 1996.

HARRISON, W.D. \& J OHNSON M.E. I mproving mapping unit delineation accuracy using Landsat MSS spectral maps. In: WESTERN REGION TECH. WORK PLANNING CONF. NAT. COOP. SOIL SURVEY. Washington, 1982. p.112-118.

HUETE, A.R. Extension of soil spectra to the satellite: atmosphere, geometric, and sensor considerations. Photointerp., 34:101-114, 1996.

HUETE, A.R. Soil influences in remotely sensed vegetationcanopy spectra. In: ASRAR, G., ed. Theory and application of optical remote sensing. Wiley Interscience, 1989. p.107141.

J ACKSON, M.L. Soil chemical analysis: advanced cource. Madison, Wisconsin University, 1969. 895p.

LABSPHERE, INC. Reflectance Calibration Laboratory. Sutton, 1996.

LEMOS, R.C. \& SANTOS, R.D. Manual de descrição e col eta de solo no campo. Campinas, Sociedade Brasileira Ciência do Solo, 1996. 46p.

MADEIRA NETTO, J .S. Spectral reflectance properties of soils. Photointerp., 34:59-70, 1996.

NANNI, M.R. \& DEMATTÊ, J .A.M. Is it possible to estimate physical-chemical soil attributes by orbital and laboratory sensors? In: INTERNATIONAL CONFERENCE ON GEOSPATIAL INFORMATION IN AGRICULTURE AND FORESTRY, 3., Ann Arbor, 2000. Proceedings. CD-ROM.

OLIVEIRA, J.B. \& PRADO, H. Carta pedológica de Piracicaba. Secretaria da Agricultura. Campinas, Instituto Agronômico de Campinas, 1989. escala 1:100,000.
RAIJ , B. van.; QUAGGIO,J .A.; CANTARELLA, H.; FERREIRA, M.E.; LOPES, A.S. \& BATAGLIA, C.O. Análise química do sol o para fins defertilidade. Campinas, Fundação Cargill, 1987. 170p.

SAHA, S.K.; KUDRAT, M. \& BHAN, S.K. Digital processing of Landsat TM data for wasteland mapping in parts of Aligarh District (Uttar Pradesh), Ind. Inter. J . Rem. Sens., 11:485492, 1990.

SHIVA PRASAD, C.R.; THAYALAN, S.; REDDY, R.S. \& REDDY P.S.A. Use of Landsat imagery for mapping soil and land resources for development planning in parts of Northern Karnataka, India. Inter. J . Rem. Sens., 11:1889-1900, 1990.

SOI L SURVEY STAFF. Keys to soil taxonomy. 8. ed. Blacksburg, 1998. 422p. (SMSS technical monograph, 6)

STONER, E.R. \& BAUMGARDNER, M.F. Characteristic variations in reflectance of surface soils. Soil Sci. Soc. Am. J ., 45:1161-1165, 1981.

TANRÉ, D.; HOLBEN, B.N. \& KAUFMAN, Y.J . Atmospheric correction algorithm for NOAA-AVHRR products: Theory and application. IEEE Trans. Geosc. RemoteSens., 30:231248, 1992.

VALERIANO, M.M.; EPIPHANIO, J .C.N.; FORMAGGIO, A.R. $\&$ OLIVEIRA, J.B. Bi-directional reflectance factor of 14 soil classes from Brazil. Int. J . Remote Sens., 16:113-128, 1995.

VENKATARATNAM, L. Use of remotely sensed data for soil mapping. Photointer. Remote Sens., 8:19-25, 1980.

VERMONTE, E.; TANRÉ, D.; HERMAN, M. \& MORCHETTE, $\mathrm{J} . J$. Second simulation of the satellite signal in the solar spectrum (6S). In: 6S User Guide Version 1, LOA-USTL, Villeneuve d'Ascq, France, 1995. 216p.

VINCENT, R.K. Expanding horizons for geological applications of multispectral and hyperspectral remote sensing data. In: INTERNATIONAL CONFERENCE, APPLIED GEOLOGIC REMOTE SENSING, 13., Vancouver, 1999. Proceedings. Ann Arbor, 1999. p.33-40.

WESTIN, F.C. \& FRAZEE, C.J . Landsat data its use in a soil survey program. Soil Sci. Soc. Am. Proc., 40:81-89, 1976.

WHITE, K.; WALDEN, J ; DRAKE, N.; ECKARDT, F. \& SETTLE, J. Mapping theiron oxide content of dune sands, Namib Sand Sea, Namíbia, using Landsat Thematic. Mapper Data. Remote Sens. Environ., 62:30-39, 1997.

ZERMIANI, M.J.T.; NANNI, M.R.; COMUNELLO, É.\& DEMATTÉ, J .A.M. Analysis of the occupation and land use in medium terrace of the Paraná rives - Brazil by GIS and remote sensing. In: INTERNATIONAL CONFERENCE ON APPLIED GEOLOGIC REMOTE SENSING, 13., Vancouver, 1999. Proceedings. Ann Arbor, 1999. v.2. p.161-167. 